\title{
EXPANSÃO DA FRONTEIRA AGRÍCOLA E MUDANÇAS NO USO DO SOLO NA REGIÃO SUL DE GOIÁS: AÇÃO ANTRÓPICA E CARACTERÍSTICAS NATURAIS DO ESPAÇO*
}

\author{
FRONTIER AGRICULTURAL EXPANSION AND LAND USE CHANGES \\ IN REGION SOUTH OF GOIÁS: ANTHROPIC ACTION AND NATURAL \\ FEATURES OF THE SPACE
}
AMPLIACIÓN DE LA FRONTERA AGRÍCOLA Y CAMBIOS EN EL USO DE LA TIERRA EN LA REGIÓN SUR DE GOIÁS: ACCIÓN ANTRÓPICA Y CARACTERÍSTICAS NATURALES DEL ESPACIO

\author{
Licius de Albuquerque Prado - Universidade Federal de Goiás - Goiânia - Goiás - Brasil \\ liciusagro@yahoo.com.br \\ Fausto Miziara - Universidade Federal de Goiás - Goiânia - Goiás - Brasil \\ fausto@fchf.ufg.br \\ Manuel Eduardo Ferreira - Universidade Federal de Goiás - Goiânia - Goiás - Brasil \\ manuel@iesa.ufg.br
}

\begin{abstract}
Resumo
Este trabalho visa a um melhor entendimento sobre a relação entre as características naturais da terra e sua utilização antrópica, demonstrando, em especial, como esta relação condicionou a expansão das fronteiras agrícolas no estado de Goiás. Para tanto, apresentamos um modelo teórico que correlaciona as variáveis topografia, tipos de solos e localização com as áreas já convertidas. As análises foram conduzidas nos municípios de Mineiros e Catalão, compreendendo as regiões Sudoeste e Sudeste do estado, respectivamente. Com imagens históricas do satélite Landsat - MSS, foram aplicados métodos de classificação supervisionada, visando à geração de mapas de uso e cobertura do solo para os anos de 1975 (Mineiros) e 1979 (Catalão). Posteriormente, os mapas foram confrontados com os dados cartográficos obtidos pelo PROBIO (Ministério do Meio Ambiente, Brasil) para 0 ano de 2002. Os resultados demonstram que as áreas de agricultura estão concentradas em regiões de topografia mais plana, com solos mais adequados e, sobretudo, próximas às principais rodovias que cortam estes municípios.
\end{abstract}

Palavras-chave: Bioma Cerrado, fronteira agrícola, modernização da agricultura, uso da terra.

\section{Abstract}

This paper aims to a better understanding about the relationship between the natural and anthropic condition of the landscapes, showing in particular how it has conditioned the expansion of agricultural frontiers in the state of Goiás. Thus, we present a theoretical model that correlates the variables topography, soil types and location with the converted areas. Our tests were conducted at the municipalities of Mineiros and Catalão, placed in the southwest and southeast regions of this state, respectively. With historical Landsat - MSS imagery, we have applied a supervised classification method in order to create maps for the land use and land cover in the years 1975 (Mineiros) and 1979 (Catalão). Subsequently, these maps were compared with the cartographic data obtained by PROBIO dataset (Ministry of Environment, Brazil) for the year 2002. The results show agricultural areas are concentrated in regions of smoother topography, suitable soils, and proximity to the major highways that cross these municipalities.

* Pesquisa financiada pela CAPES, por meio de concessão de bolsa de mestrado. 
Key-words: Cerrado Biome, agricultural frontier, modernization of agriculture, land use.

\section{Resumen}

Este trabajo apunta a una mejor comprensión de la relación entre el espacio natural y antrópico de su uso, mostrando, en particular, cómo esta relación ha condicionado la expansión de la frontera agrícola en el estado de Goiás. Se presenta un modelo teórico que se correlaciona las variables topografía, clases de suelo y la localización com la espacialización del uso de la tierra. Las pruebas se realizaron en los municipios de Mineiros y de Catalão, incluido el suroeste y sudeste del estado, respectivamente. A través de las imágenes históricas del Landsat - MSS, se han utilizado métodos de clasificación supervisada a fin de crear mapas de uso y cobertura del suelo para los años 1975 (Mineiros) y 1979 (Catalão). Posteriormente, los mapas fueron comparados con los datos cartográficos originales del PROBIO para el año 2002. Los resultados muestran que las zonas agrícolas se concentran en las zonas de topografía más plana, con suelos más adecuados y, cerca de las principales carreteras que cruzan estas ciudades.

Palabras clave: Bioma Cerrado, frontera agrícola, modernización de la agricultura, uso de la tierra.

\section{Introdução}

No estado de Goiás, a modernização da agropecuária está associada ao processo de expansão da fronteira agrícola, a qual é caracterizada, em geral, pela marcante transformação na utilização das terras e no padrão tecnológico empregado, tanto em áreas de agricultura - com correção do solo e novas técnicas de plantio -, como em áreas de pecuária, caracterizada pela substituição das pastagens naturais por pastagens plantadas (Santos, Miziara, 2008, p. 8).

Neste sentido, este trabalho discute as tendências históricas de ocupação e uso do espaço em Goiás, por meio da incorporação de um modelo teórico que explica as diversas fases de expansão da fronteira. Pretende-se, assim, contribuir com o estabelecimento de indicadores de pressão antrópica, identificando variáveis fundamentais para o monitoramento da ação humana, tais como localização, classes de solo e topografia. Dentre esses fatores, destaca-se a topografia. A dificuldade de se utilizar maquinários em regiões com relevos mais acidentados, somada à inviabilidade econômica de se eliminar tal obstáculo natural, torna a produção agrícola limitada a terrenos com menor declividade (Graziano da Silva, 2000, p. 29).

Nossa hipótese inicial é a de que os fatores naturais mencionados podem influenciar de forma marcante a ocupação de áreas de produção primária. Considerando essa hipótese, foram desenvolvidos estudos em áreas-piloto representativas, nos municípios de Mineiros e Catalão, considerados emblemáticos no processo de expansão de fronteiras. Assim, o município de Catalão foi escolhido pelo fato de apresentar um processo 
mais antigo de ocupação e uso do solo para a exploração agropecuária comercial. Em razão do fato de estar localizado em uma área com boas ligações com os centros consumidores no Sudeste do país, e de ter presenciado a chegada da ferrovia em Goiás, Catalão passou por um processo de desenvolvimento da agricultura ainda na década de 1930. Já o município de Mineiros apresenta uma expansão mais recente da Fronteira, que se intensificou notavelmente a partir da década de 1980.

Com base no exposto, a realização deste estudo vem de encontro à ausência de pesquisas históricas que expliquem, por meio de imagens de satélites e dados censitários, a influência dos fatores naturais nas transformações do espaço agrário goiano. Ressalta-se, ainda, que são raros os estudos científicos que realizam uma comparação sistemática sobre a localização das atividades agropecuárias em momentos distintos, com o objetivo de identificar a influência dos fatores naturais, como tipos de solo e topografia, a partir de mudanças significativas no padrão tecnológico.

\section{A expansão da fronteira agrícola em Goiás}

Analisando a expansão da Fronteira Agrícola em Goiás, Miziara e Ferreira (2008, p. 110) compararam este movimento à expansão da Frente Pioneira. Em ambas as etapas é possível perceber uma primeira consolidação das áreas localizadas no sul e no centro do estado, com a incorporação posterior da região norte. Um dos fatores que explica esse processo é que, originalmente, as áreas de maior fertilidade natural para a prática agrícola eram privilegiadas (Miziara, 2006, p. 180).

Outros fatores, como a infraestrutura de transportes, fundamentaram a modernização da agricultura. As rodovias federais, tais como a BR 153, a BR-070 e a BR-060, atuaram como vias de escoamento da produção dos municípios agrícolas em Goiás. Nesse sentido, a infraestrutura em geral (estradas, rede de energia elétrica, beneficiamento de grãos etc.) e a topografia são atrativos para que a atividade agrícola possa ser desenvolvida em determinada região, sendo essas áreas mais valorizadas (Ferreira et al., 2009, p. 12). Por outro lado, nas demais regiões do estado, a pastagem tende a prevalecer, por se tratar de uma atividade mais independente do que a agricultura, no que se refere, por exemplo, à topografia e à necessidade de escoamento de seus produtos.

De acordo com o modelo teórico de Miziara (2006, p. 184), a ocupação do espaço agrário goiano esteve condicionada pelos fatores naturais 
do solo e pela infraestrutura existente, especialmente, os meios de transporte. O autor defende a ideia de Renda Diferencial I e II na caracterização dos fundamentos da Fronteira Agrícola, ao enfatizar que

a decisão de investimento na agricultura está condicionada às oportunidades de lucro advindas de duas situações: a) explorar as diferentes características "naturais" do solo, determinando a renda diferencial I e b) explorar a intensificação no uso do solo já cultivado através da tecnologia, ou seja, a renda diferencial II. (Miziara, Ferreira, 2008, p. 109)

Pelo modelo teórico, as variáveis classes de solo, topografia e infraestrutura apresentam impactos diferenciados ao longo do tempo, em virtude do desenvolvimento da tecnologia. Essas evidências podem ser constatadas em Goiás, onde solos de baixa fertilidade e acidez elevada, rejeitados anteriormente para a prática da agricultura, passam a ser intensamente utilizados após a adoção de técnicas modernas de preparo e correção do solo.

A variável topográfica torna-se, então, o fator de influência do uso da terra agrícola, no lugar antes representado pela fertilidade do solo. A evidência que corrobora essa asserção é a de que, no estado de Goiás, as regiões de relevo plano são destinadas à agricultura (Ferreira, 2009, p. 38). Em compensação, a pecuária possui menos obstáculos naturais para o seu desenvolvimento.

De fato, as melhores áreas de Cerrado, sobretudo aquelas com maior fertilidade do solo, de vegetação mais densa e com relevos mais planos (solos mais profundos), foram ocupadas desde o início da chegada da frente pioneira e de expansão da agricultura no estado, segundo Ferreira (2009, p. 45). Dessa forma, a agricultura ficou destinada aos locais de solos naturalmente mais adequados, como as proximidades de Catalão (Sudeste) e Rio Verde (Sudoeste), seguida pela instalação das principais agroindústrias de Goiás.

\section{Materiais e métodos}

a) Área de Estudo

A pesquisa situou-se no estado de Goiás, mais precisamente nos municípios de Mineiros e Catalão, localizados no Sudoeste e Sudeste do estado, respectivamente. A Figura 1 ilustra a localização destes municípios: 


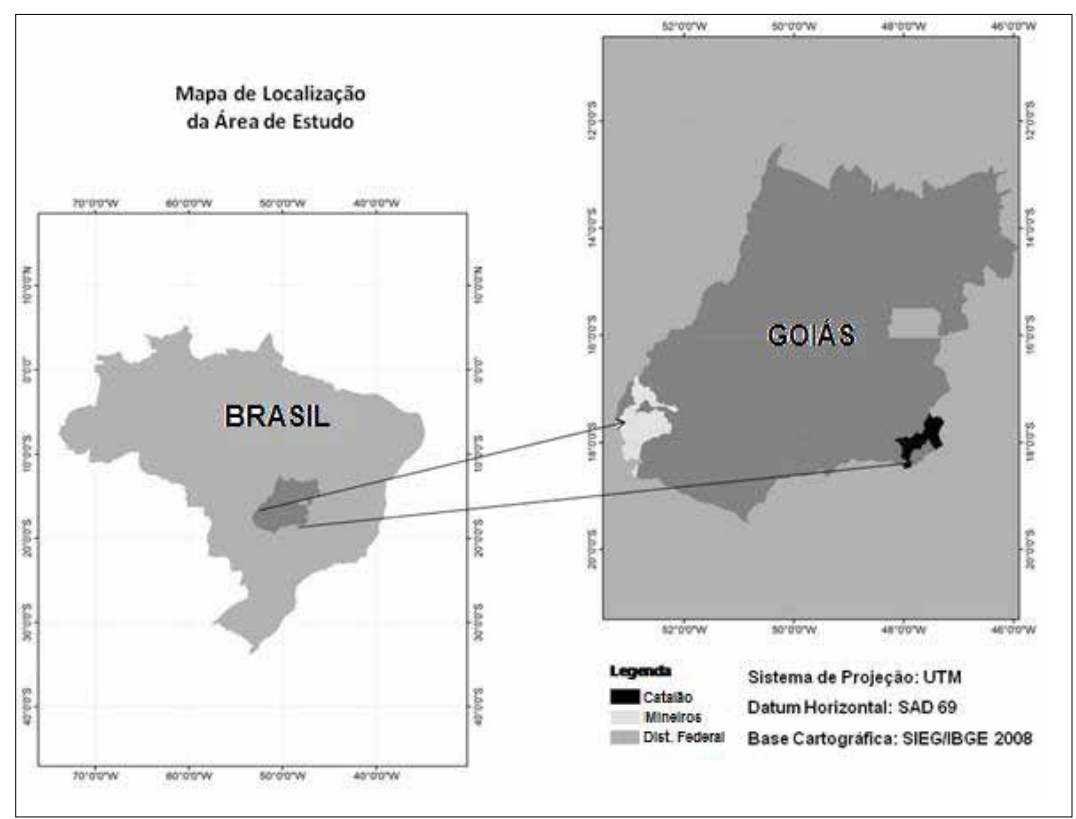

Figura 1 - Mapa de Localização dos municípios de Mineiros e Catalão no Estado de Goiás

\section{b) Bases de dados e procedimentos}

Para este estudo, foram utilizadas seis cenas (em formato digital) obtidas pela plataforma orbital Landsat - MSS, compostas de quatro bandas multiespectrais (bandas 4, 5, 6 e 7), composição colorida RGB/564, adquiridas gratuitamente no sítio do Instituto Nacional de Pesquisas Espaciais (http://www.dgi.inpe.br/CDSR). Todas as cenas são referentes à estação seca do ano, correspondendo às seguintes órbitas/pontos: 240/072 e 240/073 (7 de julho de 1975) para o município de Mineiros; 236/72, 236/73 (21 de junho de 1979), 237/72 e 237/73 (22 de junho de 1979) para o município de Catalão.

Em complemento às imagens de satélite, fez-se uso também de outras bases de dados (formatos vetorial e imagem) delimitadas para a área de estudo, dentre estas, o mapa de uso da terra elaborado pelo PROBIO/ CERRADO - Projeto de Conservação e Utilização Sustentável da Diversidade Biológica Brasileira (Sano et al., 2008, p. 153), o mapa de uso da terra elaborado pelo Projeto de Identificação de Áreas Prioritárias para a Conservação da Biodiversidade em Goiás (Ramos-Neto et al., 2004, p. 581), 
disponível em: < http://www.sieg.go.gov.br> e a imagem de relevo SRTM Shuttle Radar Topography Mission (disponível em: <http://glcfapp.umiacs. umd.edu:8080/esdi/index.jsp>).

Para a análise da cobertura vegetal, optou-se pela geração de uma imagem-realce do Índice de Vegetação (NDVI), com base nas próprias cenas MSS. Essa técnica, em conjunto com métodos de classificação supervisionada, auxiliou na diferenciação das áreas de Cerrado remanescente, culturas agrícolas e pastagem (Jensen, 2009, p. 383).

Foram estabelecidas, ao todo, quatro classes de uso do solo: Agricultura, pastagem, vegetação remanescente (Campo, Cerrado e Mata Densa) e Área urbana. A classificação supervisionada (baseada no algoritmo de Máxima Verossimilhança) consistiu na seleção de amostras de pixels das imagens para as referidas classes de uso. Dessa forma, foram confeccionados os mapas de uso e cobertura da terra para os anos de 1975 (Mineiros) e 1979 (Catalão), e comparados com os dados do PROBIO (ano-base 2002).

Para avaliar a qualidade dos mapas temáticos gerados por este estudo, foi utilizado o índice estatístico Kappa e o valor de acurácia global (Hudson; Ramm, 1987; Congalton, 1991, p. 421), obtendo-se o coeficiente de 0,79 e 83\% de acurácia para o município de Mineiros e 0,76 e 81\% de acurácia para o município de Catalão. Esses valores indicam uma boa concordância dos mapas com as imagens de satélite utilizadas como base histórica.

Para estudar a influência do fator natural topografia sobre a espacialização do uso e cobertura da terra, fez-se necessário a elaboração de um mapa clinográfico a partir dos dados SRTM (Carvalho, Latrubesse, 2004, p. 86), cujas classes de declividade foram divididas em até seis classes de intervalos: $0-2^{\circ}, 2-5^{\circ}, 5-10^{\circ}, 10-20^{\circ}, 20-45^{\circ}$ e $>45^{\circ}$. Para analisar o fator natural localização, foi gerado o mapa de buffers ou zonas tampão, utilizando-se raios de até $10 \mathrm{~km}$ ao redor da malha viária nos municípios estudados. Por fim, foi elaborado o mapa de solos para Goiás, com base em dados disponibilizados pelo Sistema Estadual de Estatística e de Informações Geográficas de Goiás (SIEG), na escala de 1:250.000. Tendo em vista a análise temporal dos dados, todos os mapas desenvolvidos foram sobrepostos ao mapa de uso e cobertura da terra de 2002 (base PROBIO).

\section{Resultados e discussão}

Em Mineiros, a partir das técnicas de processamento digital aplicadas às imagens orbitais de 1975, foi possível obter valores percentuais das classes 
de uso e cobertura da terra para aquele ano, comparados com os resultados apresentados pelo PROBIO, para o ano de 2002. Dentre os resultados desta análise, observou-se que a agricultura, em 1975, ocupava uma área relativa do município de Mineiros de apenas 2,36\%, ao passo que, em 2002, ela já representava $13,34 \%$ da área total do município, o que corresponde a um aumento superior a cinco vezes à área de agricultura em 1975.

Em relação à classe de uso pastagem, podemos afirmar que ocorreram mudanças na espacialização dessa classe no decorrer dos últimos 30 anos. Ao mesmo tempo em que uma parcela considerável de pastagem nativa foi convertida em agricultura (30\%), a área total de pastagem se manteve quase que a mesma de 1975, em virtude da expansão da pecuária para áreas de vegetação nativa, em proporção equivalente ao percentual perdido para o cultivo agrícola. A perda de $11 \%$ da vegetação natural do município de Mineiros corrobora esta constatação, reforçando a tese de que tanto a agricultura (em menor proporção) quanto a pecuária utilizaram-se das áreas de vegetação natural para se expandirem (Figura 2).

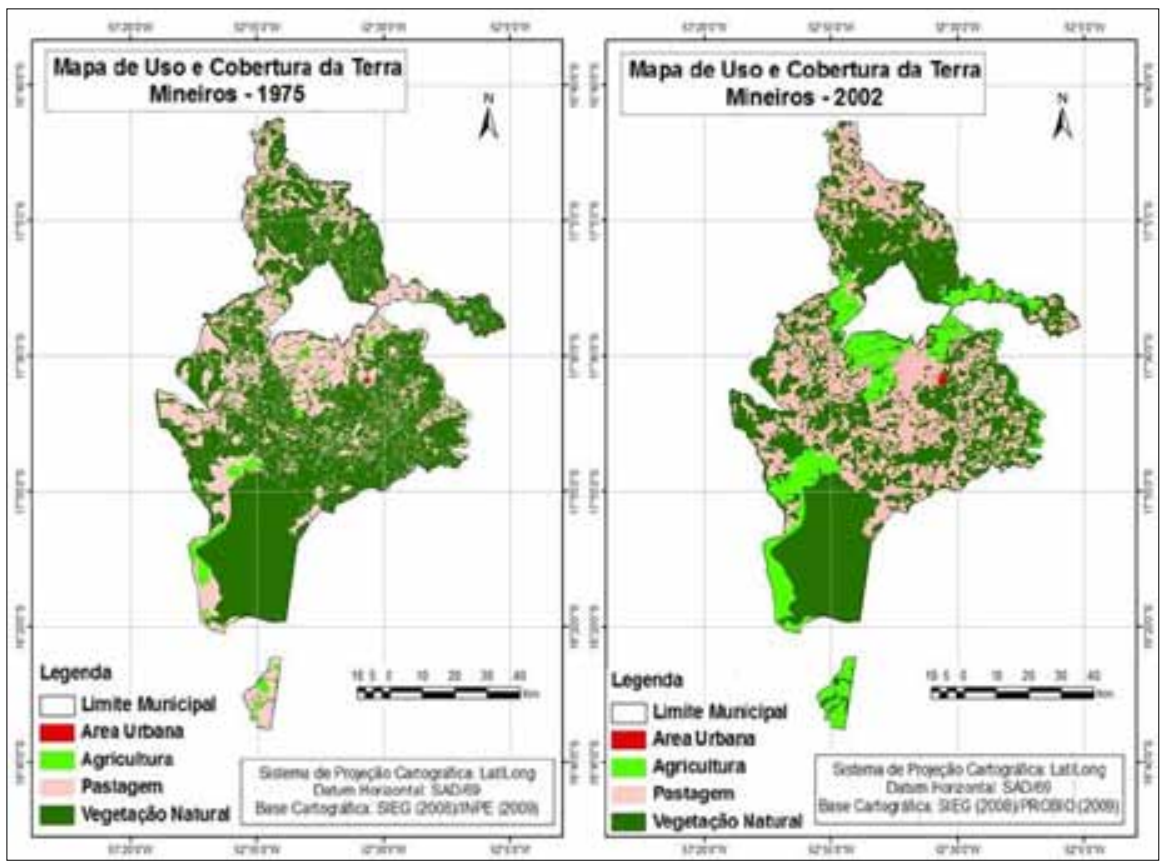

Figura 2 - Mapa de uso e cobertura da terra do município de Mineiros-G0 para os anos de 1975 e 2002 
Quando analisamos as classes de uso do solo em razão da topografia, vemos que a agricultura está presente em maior quantidade nas áreas com declividade entre 0 e $2^{\circ}$. No geral, em 1975, 83\% da área total de agricultura do município de Mineiros estava situada nesta faixa de declividade. Ao se estender a declividade para até $5^{\circ}$, o percentual de agricultura é ampliado para 97\% em 1975, e 96\% no ano de 2002.

A pastagem, da mesma forma que a classe de agricultura, é encontrada em maior quantidade nos terrenos mais planos, ainda que consiga se adaptar melhor que a agricultura nas áreas de declives mais acentuados. Com base nesta constatação, observa-se que, em 1975, 85\% das pastagens encontravam-se em áreas de até $5^{\circ}$, ao passo que, em 2002, esse percentual correspondia a $83 \%$.

Analisando os percentuais das classes de agricultura, pastagem e vegetação natural, podemos afirmar que, quanto maior a declividade, maior a presença de vegetação natural (Figura 3). A lógica é que, se a topografia do terreno não favorece o cultivo da pastagem e de outras culturas agrícolas, a vegetação natural tende a predominar. Ao contrário, quanto menor a declividade, maior o percentual de áreas destinadas às práticas agropecuárias. Assim, para o período analisado, observa-se que a vegetação natural perdeu áreas nas declividades entre 0 e $5^{\circ}$.

Por sua vez, os solos exercem influência sobre a agricultura, que tende a se estabelecer em solos de boa estrutura e bem drenados. Em 1975, cerca de $18 \%$ da agricultura, no município de Mineiros, estava concentrada nos solos Gleissolos e 75\%, nos solos Latossolos. Em 2002, esses percentuais eram de $40 \%$ e $50 \%$, respectivamente. De modo geral, são solos com topografia suave, cuja combinação entre fatores naturais e investimento tecnológico favorece o desenvolvimento de atividades mais intensivas de capitais. No caso dos solos Gleissolos, ainda que possuam drenagem ineficiente (nível freático próximo à superfície), o incremento de capital (tecnologia de correção) permite a exploração agrícola desses terrenos. 


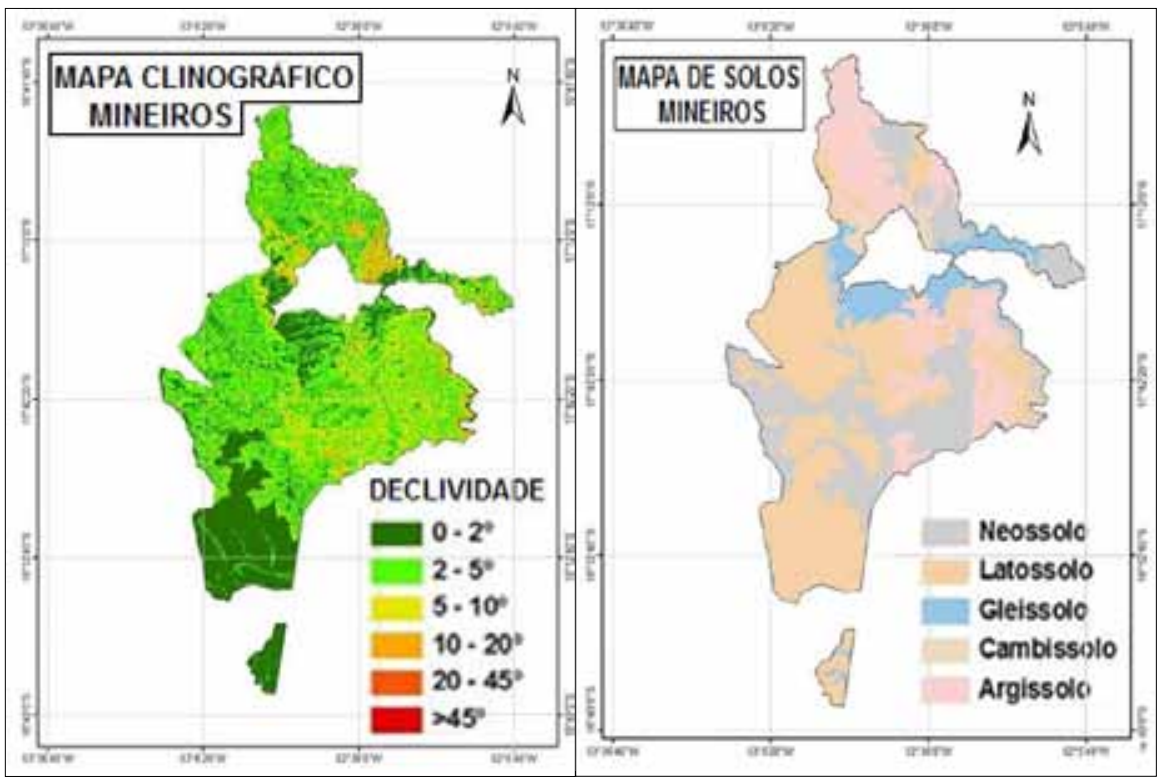

Figura 3 - Mapa Clinográfico e Mapa de Solos para o município de Mineiros-G0

Em relação à variável localização, os dados obtidos puderam comprovar que a ocorrência da agricultura, no município de Mineiros, é positivamente relacionada com a proximidade das estradas. Em 1975, aproximadamente $22 \%$ da agricultura do município estava localizada até $1 \mathrm{~km}$ das rodovias. Esse percentual é maior que o da pastagem e da vegetação natural, com 12\% e 8\%, respectivamente. Em 2002, embora a área de agricultura no primeiro quilômetro (16\%) seja menor que em 1975, ainda é a maior área quando comparada às outras classes de uso e cobertura da terra (Figura 4).

No geral, todos os dados encontrados com relação a solos, declividade e distância das estradas permitem identificar um processo histórico, uma vez que as áreas que apresentam uma melhor combinação das variáveis topografia, solos propícios e localização foram ocupadas em primeiro lugar. No caso do município de Mineiros, essa ocupação inicial foi realizada pela pecuária, como, aliás, em toda a região de Cerrado. É interessante constatar que a pecuária, na medida em que demanda níveis menores de investimento, vis-à-vis a agricultura, de modo geral, é a atividade de primeira ocupação do espaço. 


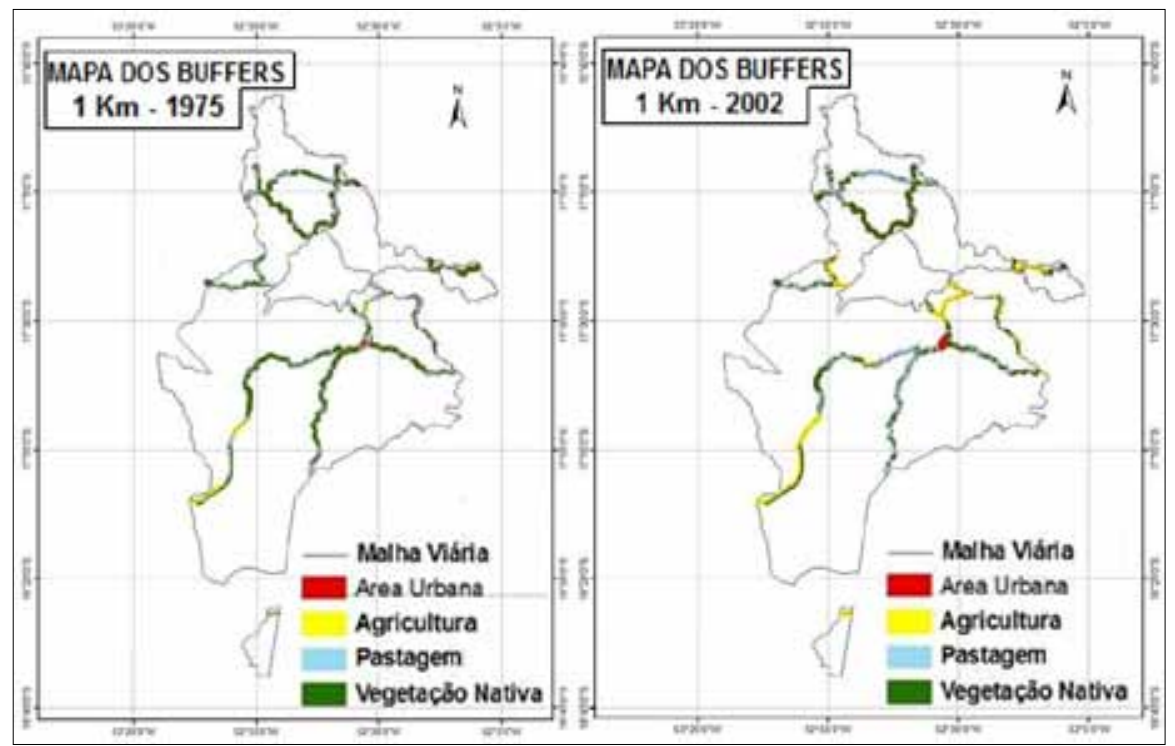

Figura 4 - Mapa dos Buffers para o município de Mineiros-G0

De acordo com o modelo teórico apresentado, podemos constatar que existe uma relação positiva entre a Renda Diferencial I e a Renda Diferencial II, isto é, uma relação positiva entre o uso do melhor solo (considerando uma combinação específica de fatores) pelas atividades que demandam maior investimento.

Para o município de Catalão, os dados da pesquisa permitem observar que o crescimento da agricultura ocorreu especialmente em áreas utilizadas pela pastagem. A área de pastagem convertida em agricultura é 2,7 vezes maior que a área de vegetação natural ocupada por essa atividade. Entretanto, diferentemente do que ocorreu no município de Mineiros, a pastagem não conseguiu recuperar a área perdida para a agricultura, pois pouco avançou sobre as áreas de vegetação natural até 2002.

Na análise temporal das mudanças de uso do solo, 47\% das áreas com cultivos agrícolas comerciais, identificadas em 1979, mantinham a mesma atividade no ano de 2002 (dados PROBIO). Na classe de pastagem, 18\% dessa área (cerca de 35.000 hectares) foi convertida para a agricultura. Esses números demonstram que a agricultura em Catalão expandiu-se, sobretudo, para áreas anteriormente utilizadas pela pastagem, mas também 
ocupou, em quantidades consideráveis, áreas utilizadas pela vegetação natural (Figura 5). No geral, a agricultura foi responsável pela conversão de $8,4 \%$ da área total de vegetação natural presente no município.

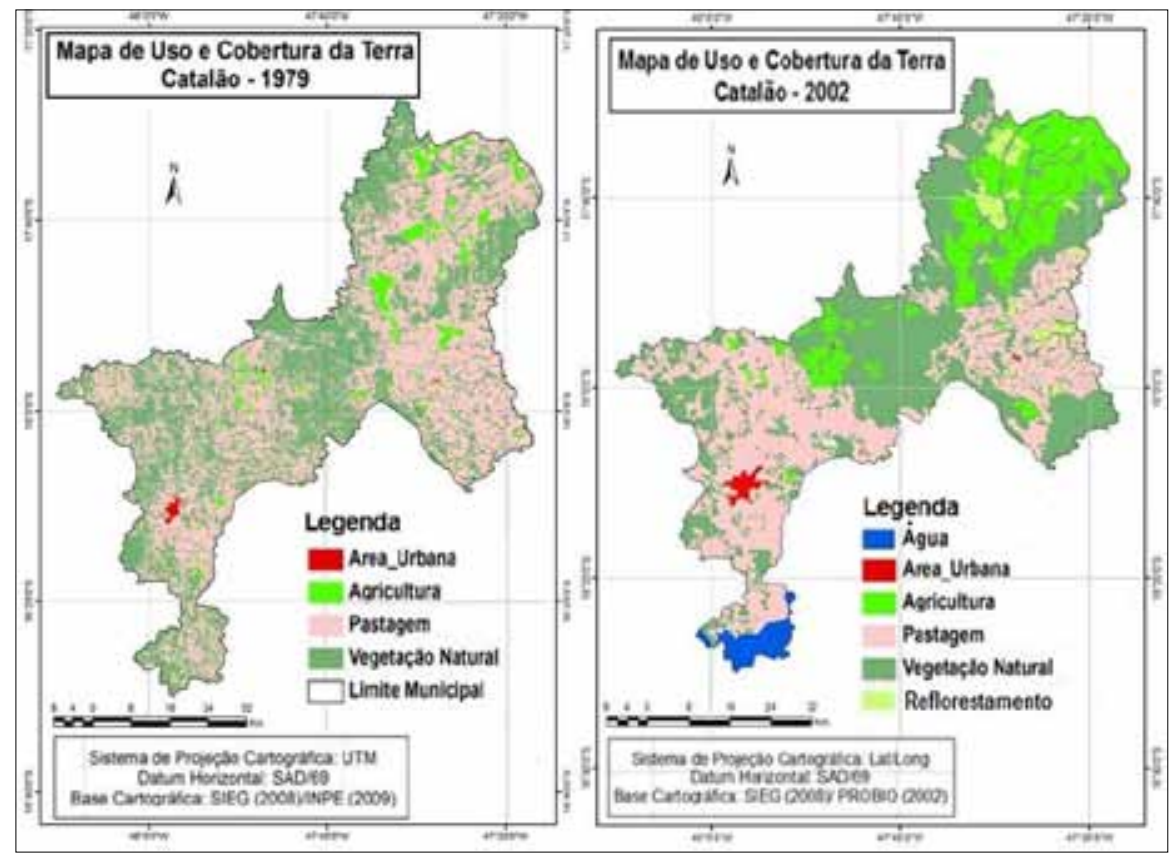

Figura 5 - Mapa de uso e cobertura da terra do município de Catalão-G0 para os anos de 1979 e 2002

A análise da influência da variável topografia, em Catalão, sobre a agricultura permite constatar que, em 1979, essa atividade estava concentrada (cerca de 55\%) em terrenos com declividade entre 0 e $2^{\circ}$. Ao se estender até $5^{\circ}$, as áreas agrícolas somavam $89 \%$ da área total de agricultura em 1979, e 94\% em 2002, indicando a tendência de expansão da agricultura para as áreas de relevo plano (Figura 6).

Também a pastagem em Catalão encontrava-se localizada, em sua maior parte, em terrenos mais planos. No entanto, o percentual de pastagem nas declividades de até $5^{\circ}$ é menor que o percentual identificado para as áreas de agricultura (isto é, 76\% em 1979 e 78\% em 2002). Proporcionalmente, a pastagem se expandiu em menor quantidade para áreas mais 
planas do município, quando comparada com a agricultura. Já a vegetação natural permaneceu ocupando as áreas com maior declividade.

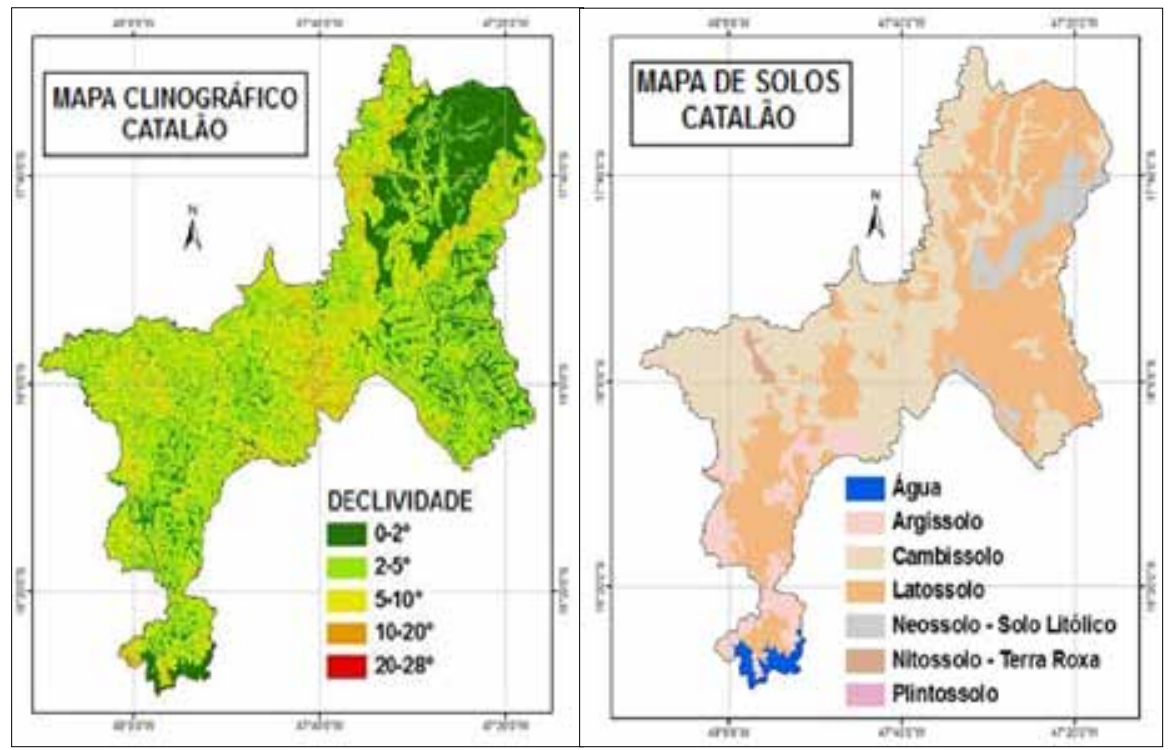

Figura 6 - Mapa clinográfico e mapa de solos para o município de Catalão-G0

Em relação aos solos, observa-se que, em 1979, apenas três categorias de solos eram utilizadas pela agricultura de Catalão. Da área total agrícola, 78\% estavam localizados nos Latossolos; 20\%, nos Cambissolos e menos de 2\%, nos Argissolos. Em 2002, como resultado das técnicas de modificação e correção do solo, a agricultura passa a ocupar cinco diferentes tipos de solos, dos quais os Latossolos e os Cambissolos são os mais utilizados, seguidos dos Neossolos, Nitossolos e Argissolos (estes em pequenas quantidades).

No que concerne à influência da variável localização, também é possível comprovar uma relação positiva da agricultura com a proximidade das estradas. Em 1979, pouco mais de 36\% da agricultura em Catalão localizava-se na área de influência das estradas (até $1 \mathrm{~km}$ de distância), enquanto o percentual para a pastagem era de apenas $24 \%$. Neste caso, a pecuária demonstra ser menos dependente que a agricultura quanto à presença de vias de escoamento. Para 2002, a ampliação da malha viária do 
município e a melhoria nos transportes possibilitaram à agricultura uma expansão para as áreas mais afastadas, não cultivadas até 1979 (Figura 7).

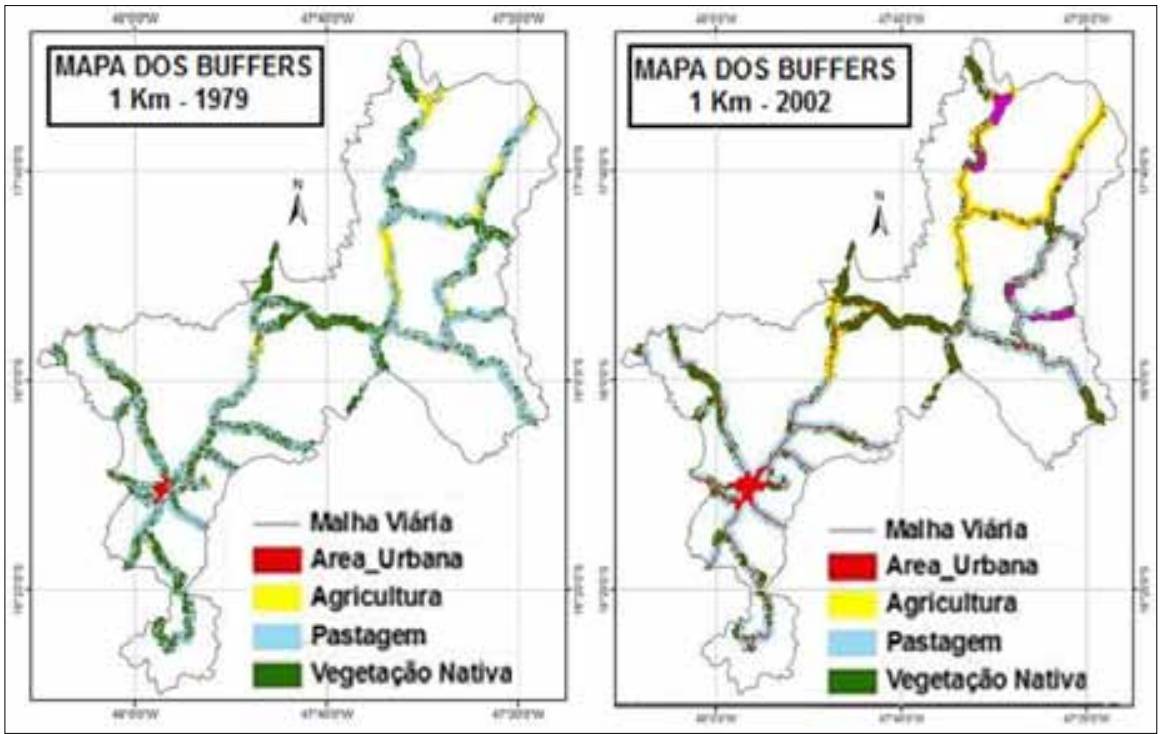

Figura 7 - Mapa dos Buffers para o município de Catalão-G0

Como esperado, as áreas de vegetação natural apresentam um comportamento inverso ao da agricultura e pecuária, ou seja, quanto mais afastadas das estradas, maior o percentual desta, e menor o percentual das atividades antrópicas.

Considerações finais

Ao comparar os municípios de Mineiros e Catalão, percebemos que o segundo apresenta um processo histórico mais antigo de ocupação. Por exemplo, a chegada da estrada de ferro em Goiás se dá primeiramente pela região sudeste, passando por Catalão. Isso implica um processo de antropização do espaço mais consolidado. Assim, quando a fronteira agrícola avança sobre o município, a agricultura se expande sobre áreas já convertidas, em geral, ocupadas pela atividade de pastagem.

Já no caso de Mineiros, como representa uma situação mais recente de ocupação produtiva do espaço, presencia-se uma expansão mais sig- 
nificativa de áreas antropizadas. A agricultura, grosso modo, se expande sobre áreas de pastagem que, por sua vez, tende a ocupar áreas de vegetação nativa.

Esse processo reflete a importância das determinações históricas na expansão das atividades humanas sobre novas fronteiras. Mesmo antes da chegada da moderna tecnologia agropecuária, associada aqui com o nome "Fronteira Agrícola", é possível constatar que os locais primeiramente ocupados são aqueles que oferecem a melhor solução na articulação de variáveis como topografia, solos propícios e localização. Mesmo que essas atividades sejam pouco significativas em relação a investimento, como uma pecuária de caráter mais extensivo, a ocupação inicial privilegia áreas mais "nobres".

Assim, sugerimos, neste estudo, uma nova abordagem sobre as áreas antropizadas no bioma Cerrado, a qual normalmente estava condicionada à presença ou ausência de atividade humana. Consideramos como mais proveitoso uma perspectiva que identificasse níveis de atividade humana. Muitas vezes, o que se considera como "cerrado ralo", por exemplo, é resultado de uma preparação de pastagem natural, com a derrubada de uma vegetação de maior porte. Ademais, esperamos que as informações aqui prestadas auxiliem no monitoramento sistemático das regiões que passam por um processo de modificação em seu espaço agrário, orientando as políticas públicas voltadas para a preservação do meio ambiente e o equilíbrio das estruturas fundiárias.

\section{Referências}

CARVALHO, T. M.; LATRUBESSE, E. M. Aplicação de modelos digitais do terreno (MDT) em análises macrogeomorfológicas: o caso da bacia hidrográfica do Araguaia. Revista Brasileira de Geomorfologia, São Paulo, v. 5, n. 1, p. 85-93, 2004.

CONGALTON, R.G. A Review of Assessing the Accuracy of Classifications of Remotely Sensed Data. Remote Sensing of Environment, USA, v. 37, n. 1, p. 3546, 1991.

FERREIRA, M. E. Modelagem da dinâmica de paisagem do cerrado. Tese (Doutorado) - Universidade Federal de Goiás, Programa Multidisciplinar de Doutorado em Ciências Ambientais, Goiânia, 2009. 115 p.

FERREIRA, M. E. et al. Ativos ambientais do bioma Cerrado: uma análise da cobertura vegetal nativa e sua relação com o preço da terra no Estado de Goiás. Revista Brasileira de Cartografia, v. 61, n. 1, p. 37-50, 2009. 
GRAZIANO DA SILVA, J. Tecnologia e agricultura familiar. Porto Alegre: Ed. da Universidade Federal do Rio Grande do Sul, 2000. 238 p.

HUDSON, W. D.; RAMM, C. W. Correct formulation of the Kappa coefficient of agreement. Photogrammetric Engineering and Remote Sensing, v. 53, n. 4, p. 421422, 1987.

JENSEN, J. R. Sensoriamento remoto do ambiente: uma perspectiva em recursos terrestres (Tradução da segunda edição). São José dos Campos: Parêntese, 2009. $598 \mathrm{p}$.

MIZIARA, F. Expansão de fronteiras e ocupação do espaço no Cerrado: o caso de Goiás. In: GUIMARÃES, L. D.; SILVA, M. A. D. da; ANACLETO, T. C. (Orgs.). Natureza viva Cerrado. Goiânia: Ed. da UCG, 2006. cap. VII, p. 169-196.

MIZIARA, F.; FERREIRA, N. C. Expansão da fronteira agrícola e evolução da ocupação e uso do espaço no Estado de Goiás: subsídios à política ambiental. In: FERREIRA, L. G. (Org.). A encruzilhada socioambiental - biodiversidade, economia e sustentabilidade no cerrado. Goiânia: Cânone/Cegraf-UFG, 2008. cap. IV, p. 107-125.

RAMOS-NETO, M. B. et al. Revisão das áreas prioritárias para a conservação do cerrado - delimitação e banco de dados. In: IV CONGRESSO BRASILEIRO DE UNIDADES DE CONSERVAÇÃO, 1, Curitiba, 2004. Anais..., v. 1, Curitiba, Fundação O Boticário de Proteção à Natureza, 2004. p. 581-590.

SANO, E. E. et al. Mapeamento semidetalhado (escala de 1:250.000) da cobertura vegetal antrópica do bioma Cerrado. Pesquisa Agropecuária Brasileira, BrasíliaDF, v. 43, n. 1, p. 153-156. 2008.

SANTOS, F. P.; MIZIARA, F. A expansão da Fronteira Agrícola em Goiás: análise da influência das características "naturais" do espaço. In: IV ENCONTRO NACIONAL DA ANPPAS, Brasília, DF, 2008. Anais do IV Encontro Nacional da Anppas, Brasília, 2008. p. 1-12.

Licius de Albuquerque Prado - Engenheiro Agrônomo pela Universidade Federal de Goiás. Tecnólogo em Geoprocessamento pelo Instituto Federal de Goiás. Mestre em Agronegócio pela Universidade Federal de Goiás.

Fausto Miziara - Sociólogo, mestre em Sociologia e doutor pela Universidade de Brasília. Atualmente é professor da Universidade Federal de Goiás.

Manuel Eduardo Ferreira - Geógrafo e mestre em Processamento de Dados em Geologia e Análise Ambiental pela Universidade de Brasília. Doutor em Ciências Ambientais pela Universidade Federal de Goiás. Atualmente é professor da Universidade Federal de Goiás. 